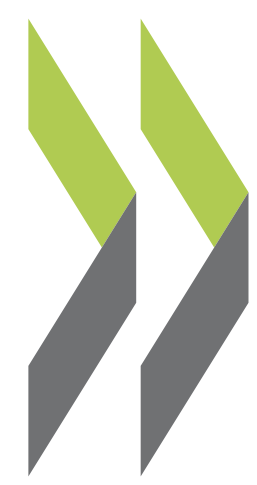

PEB Exchange, Programme on Educational Building 2005/09

\title{
Energy-Efficient Renovation of Educational Buildings
}

\section{Heike Erhorn-Kluttig,}

\author{
Ove Mørck
}




\section{ENERGY-EFFICIENT RENOVATION OF EDUCATIONAL BUILDINGS}

Case studies demonstrating energy-efficient renovation of educational buildings collected by the International Energy Agency (IEA) provide information on retrofit technologies, energy-saving approaches and ventilation strategies. Some general findings are presented here along with one case study, Egebjerg School in Denmark, which shows how natural ventilation can be incorporated into a refurbishment project.

Researchers from ten countries collected 25 case studies of retrofit measures as part of the IEA's work to develop the Energy Concept Adviser, an Internet-based retrofit tool for decision-makers (see PEB Exchange no. 53, October 2004). The case studies comprised 18 schools, six universities and one day-care centre from the United States and nine European countries: Denmark, Finland, France, Germany, Greece, Italy, Norway, Poland and the United Kingdom.

\section{Retrofit technologies}

The energy retrofit technologies evident in the case studies included improving the building envelope, lighting, heating, cooling and ventilation, as well as the use of solar energy. Not surprisingly, among the projects traditional energy conservation technologies were applied most often, i.e. added insulation, low-emissivity coated windows, efficient electrical lighting systems and new heating systems. More recent concepts such as natural hybrid ventilation and demand-controlled ventilation were implemented in slightly more than $30 \%$ of the projects. Likewise in approximately one third of the projects, daylighting principles and improved control of the artificial lighting systems were applied.

\section{Energy-saving approaches}

The case studies revealed three approaches which resulted in differing amounts of energy savings. The studies showing higher savings were generally demonstration projects in which several energy saving technologies were implemented as part of a holistic approach. However payback times were long. In contrast, for the projects showing relatively smaller savings, fewer technologies were applied and more emphasis was placed on a cost-effective approach resulting in fairly low payback times of the order of five years. In other projects the main emphasis was on improving indoor comfort, air quality or lighting comfort, and the energy savings were considered secondary.

The energy savings of the different projects varied greatly (see figures $1 \mathrm{a}$ and $1 \mathrm{~b}$ ) and for some projects were considerable: up to $55-75 \%$ for heating and 30 $40 \%$ for electricity. Heating energy consumption, for example, for the Danish and German projects before retrofit were $200-280 \mathrm{kWh} / \mathrm{m}^{2} /$ year and were reduced to $50-90 \mathrm{kWh} / \mathrm{m}^{2} /$ year. At the other end of the scale the projects in United Kingdom and the United States reported more modest savings of $8-20 \%$ for heating and around $15 \%$ for electricity.

Figure 1a. Heating energy savings (Selected case studies)

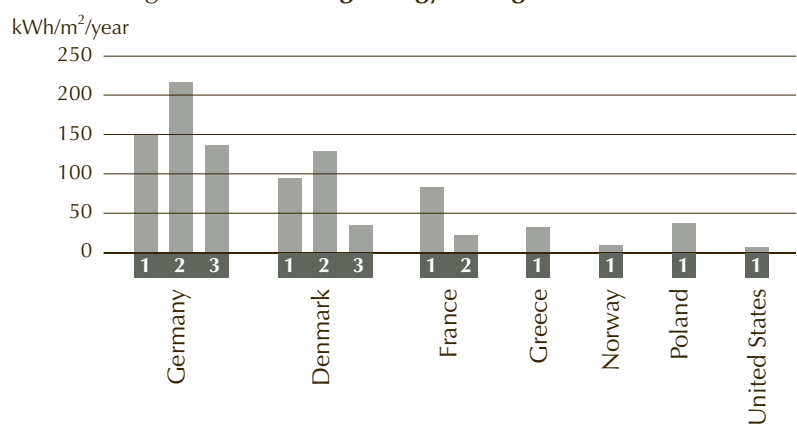

Figure 1b. Electrical energy savings (Selected case studies) $\mathrm{kWh} / \mathrm{m}^{2} /$ year

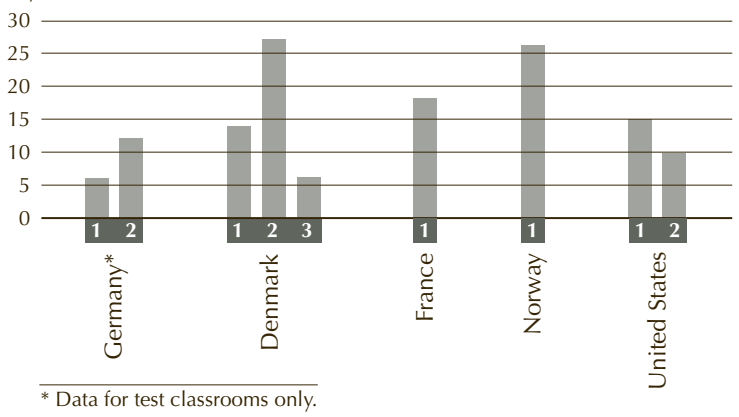

\section{Ventilation strategies}

A comparison between the 25 retrofit projects showed that schools in different countries followed different ventilation strategies. Finland emphasised indoor air quality and tried to improve this with mechanical ventilation with heat recovery. Denmark and Norway tended to replace mechanical ventilation with natural hybrid ventilation that can be supported if necessary with fans. France worked either with a minimum air change rate provided by a mechanical ventilation system and additional ventilation from opening the windows or with only natural ventilation from the windows. Germany showed three different natural ventilation strategies in its three retrofitted schools: first by simply opening the windows, second with pre-heating/pre-cooling by atria, and third through 
shafts into the classrooms and from there to corridors, supported by fans. The Polish school was ventilated uniquely by opening the windows. Though the United Kingdom's retrofit project did not deal expressly with ventilation strategies, the schools presented were generally ventilated by opening the windows, and sometimes mechanical ventilation was provided by fans or draft support. The two US schools were mainly

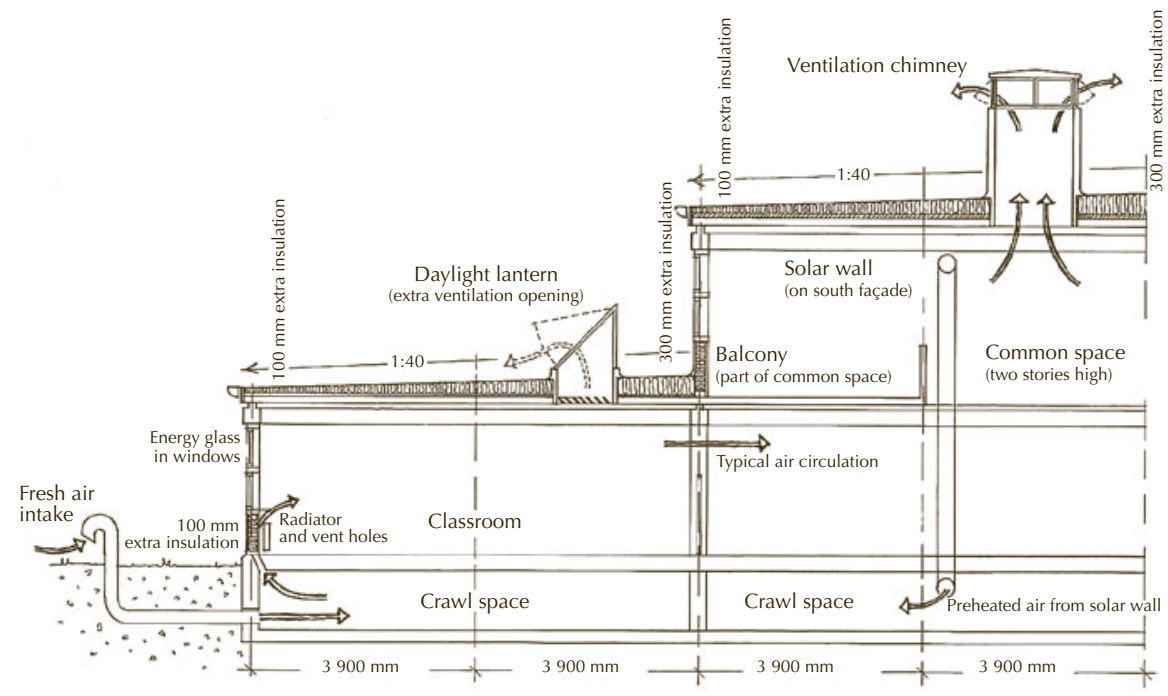
ventilated through the windows and in one case by an additional mechanical system with heat recovery.

Technical section of the Egebjerg School showing the ventilation system

\section{Egebjerg School, Denmark}

The aim of this Danish project was to demonstrate that an energy-efficient and ecological refurbishment of a school built in the 1970 s could produce a healthy indoor climate at a reasonable cost. Modern building technology was combined with natural ventilation and active solar heating, and materials were carefully chosen. The project concerned a selected part of Egebjerg School containing classrooms, corridors and two double-height common area rooms.

The design concept focused on reducing heat losses through the roof, façades and windows and replacing the existing mechanical ventilation system with a natural ventilation system. A new sloped roof construction replaced the original flat roof, and an average of $20 \mathrm{~cm}$ of mineral wool was added, giving $30 \mathrm{~cm}$ thick insulation overall. All façades were completely renewed and also furnished with $20 \mathrm{~cm}$ of mineral wool insulation. The windows in the selected sections of the school were replaced with low-energy windows with a $U$-value of $1.7 \mathrm{~W} / \mathrm{m}^{2} \mathrm{~K}$.

An entirely new natural ventilation system was designed. Fresh air is taken in through air ducts to a crawl space below the classrooms. From the crawl space the air is led into each classroom behind convector radiators designed to further preheat the air. Air leaves the classrooms through corridors to the double-height common assembly room whose roof has a wind and

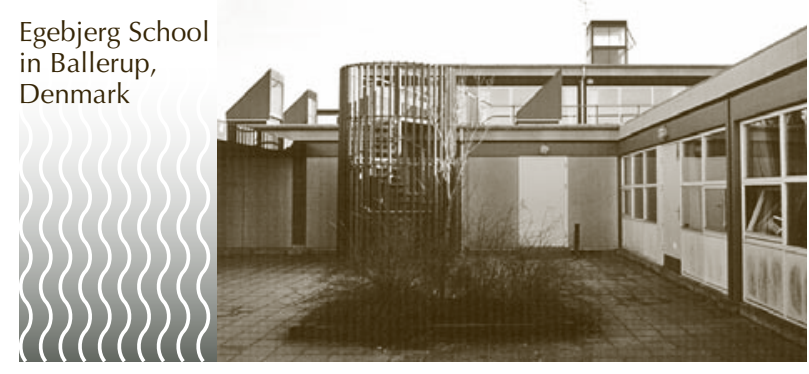

solar chimney. The chimney is designed to work by a combination of wind pressure and ordinary stack effect. Two separate chambers in the chimney serve as solar air collectors; when the temperature increases to a certain degree, the pressure created opens them - a feature primarily designed for summer operation. A fan is located in the crawl space to generate a slight overpressure in case the natural pressure is too weak to generate the necessary ventilation. A type of solar air collector called a "Canadian solar wall" is installed on the south façade of the two-storey building. Air is taken into the crawl space, from the collector instead of from the earth ducts, whenever it is preheated to a higher temperature.

\section{Energy consumption at Egebjerg School}

\begin{tabular}{l|l|l}
\hline & Before refurbishment & After refurbishment \\
\hline Heating & $181 \mathrm{kWh} / \mathrm{m}^{2}$ & $87.3 \mathrm{kWh} / \mathrm{m}^{2}$ \\
\hline $\begin{array}{l}\text { Electricity for } \\
\text { ventilation and } \\
\text { lighting }\end{array}$ & $36 \mathrm{kWh} / \mathrm{m}^{2}$ & $22 \mathrm{kWh} / \mathrm{m}^{2}$ \\
\hline
\end{tabular}

Following the retrofit, pupils and teachers who answered a questionnaire reported an overall improvement in the school's indoor comfort quality including a positive change in air quality as a result of the refurbishment.

Reference
Mørck, O. (editor) (2003), "IEA ECBCS Annex 36: Retrofitting in
Educational Buildings - REDUCE. 25 Case Study Reports from
10 different Countries".

Article by:

Heike Erhorn-Kluttig, Fraunhofer Institute of Building Physics, Stuttgart, Germany, e-mail: hk@ibp.fhg.de and Ove Mørck

Cenergia Energy Consultants, Ballerup, Denmark

E-mail:ocm@cenergia.dk

Web site: www.annex36.com 